\title{
Conflitos por reconhecimento na modernidade periférica entre a igualdade e a distinção
}

\author{
Marcelo Kunrath Silva * \\ Fernando Canto Michelotti * *
}

\section{Resumo}

Este artigo parte do argumento de que a categoria do reconhecimento, na modernidade periférica, se depara com uma configuração social bastante diferenciada do contexto no qual foi originalmente elaborada, para discutir o quanto as lutas por reconhecimento podem acabar por fundamentar e legitimar a desigualdade social no país. Em países como o Brasil, o acesso ao reconhecimento social tende a se construir não pela luta para ser reconhecido como sujeito portador de direitos, mas, ao contrário, pela luta para marcar uma distinção que possibilite usufruir os ganhos materiais e simbólicos associados a esta posição diferenciada. Com o intuito de explorar as possibilidades analíticas abertas por este argumento, o artigo enfoca experiências de organização coletiva de catadores de materiais recicláveis no estado do Rio Grande do Sul. Demonstra-se que, em oposição aos discursos e intencionalidades que orientam a atuação das organizações investigadas, as lutas por reconhecimento que elas desenvolvem são, em grande medida, marcadas por um esforço para se distinguir de outros que se situam na mesma condição de subalternidade, estabelecendo uma competição pelo acesso a determinados bens materiais e simbólicos escassos.

Palavras-chave: modernidade periférica, reconhecimento social, distinção, catadores.

* Professor do Departamento de Sociologia e dos Programas de Pós-Graduação em Sociologia e em Desenvolvimento Rural - Universidade Federal do Rio Grande do Sul. Endereço eletrônico:mksilva@ufrgs.br

橉 Doutorando em Sociologia/ Programa de Pós-Graduação em Sociologia - Universidade Federal do Rio Grande do Sul. E-mail: fcmichelotti@yahoo.com.br 


\section{Introdução}

$\mathrm{O}$ debate da teoria do reconhecimento social, a despeito de controvérsias e ambiguiidades entre os autores contemporâneos que vêm debruçando-se sobre esse tema, emerge de contextos sociais nos quais vigora, hipoteticamente, uma noção de reconhecimento fundada sobre princípios universalistas e igualitários. A perspectiva que predomina é a de que os indivíduos constroem sua dignidade e autenticidade à medida que experimentam um conjunto de direitos e deveres comuns, ao mesmo tempo em que estes são interpretados como inerentes à própria condição de membros de uma comunidade de iguais, ou seja, inerentes à condição compartilhada de serem cidadãos. Em seu contexto original, então, a categoria do reconhecimento social compartilha de um princípio de igualdade socialmente disseminado, cuja incorporação ao substrato social serviu, inclusive, de base para sustentar reivindicações mais recentes pelo reconhecimento de identidades específicas, frente à emergência dos "riscos da sinonímia entre igualdade e homogeneidade" (LAVALLE, 2003, p.82). A existência de um parâmetro de igualdade que rege as relações sociais torna-se a garantia de que os "diferentes" tenham o direito de ter sua diferença reconhecida não como um elemento de desqualificação, mas, ao contrário, como base de dignidade e valorização social. Em se tratando de estratégias coletivas que se orientam pela busca de reconhecimento social, elas tenderão, assim, a incorporar a luta tanto pelo direito de todos a determinados padrões de igualdade quanto pelo direito de terem suas diferenças valorizadas.

Este artigo propõe-se a discutir a hipótese de que, em contextos sociais nos quais imperam altos índices de desigualdade e inexiste um princípio de igualdade socialmente instituído, a busca pelo reconhecimento tende a orientar-se não pela universalização de determinados padrões sociais e legalmente instituídos de igualdade/ diferença, mas, em grande medida, por esforços individuais e/ou coletivos para acessar e usufruir privilégios associados às posições diferenciadas que configuram a hierarquia social. Na medida em que o valor dos indivíduos e grupos sociais na ordem hierárquica depende da posição por eles ocupada, o reconhecimento social não 
se funda no gozo de um suposto estatuto igualitário de cidadão, mas sim na capacidade de desenvolver estratégias de distinção (BOURDIEU, 1974) que possibilitem usufruir os ganhos materiais e simbólicos associados às distintas posições do espaço social. $\mathrm{O}$ argumento desenvolvido neste artigo, portanto, é o de que as lutas por reconhecimento, especialmente no contexto da "modernidade periférica" (SOUZA, 2003), podem acabar traduzindo-se em lutas por distinção, na medida em que emergem de configurações sociais nas quais é importante se distinguir para ser socialmente reconhecido e valorizado. Assim, o presente artigo compartilha da perspectiva de Souza (idem, p.87), para quem:

"A teoria do reconhecimento (...) pode (...) dar conta do mecanismo generativo do 'consenso normativo mínimo' compartilhado intersubjetivamente e que, na realidade, contextualiza e filtra as chances relativas de monopólio legítimo na distribuição dos recursos escassos pelas diversas classes sociais em disputa em uma dada sociedade".

Com o intuito de explorar as possibilidades analíticas abertas por esse argumento, o artigo enfoca experiências de organização coletiva de catadores de materiais recicláveis no estado do Rio Grande do Sul, a partir de uma pesquisa empírica feita com uma federação de associações de catadores e um movimento social vinculado a essa mesma temática. Acredita-se que analisar a atuação destes atores, mediante a adoção de uma perspectiva crítica e contextualizada da teoria do reconhecimento social, possa constituir-se em uma alternativa analítica fértil para abordar as razões da persistência de múltiplos padrões interligados de desigualdade - sociais, econômicos, políticos e culturais - que, apesar das profundas mudanças pelas quais passou o Brasil nos últimos 50 anos (SANTOS, 2006), ainda bloqueiam a construção de uma cidadania igualitária e universalista no país.

\section{A igualdade na base da teoria do reconhecimento social}

Nesta seção, pretende-se tecer algumas considerações que permitam elucidar como, no âmbito da teoria do reconhecimento 
social, configura-se a relação intrínseca entre igualdade e demandas de reconhecimento na contemporaneidade, pois é ela que será problematizada ao longo do artigo.

Dentre os autores que estudam a emergência social das reivindicações de reconhecimento em países centrais, Nancy Fraser e Charles Taylor evidenciam duas abordagens distintas da teoria do reconhecimento social, ainda que esses diferentes enfoques não sejam suficientes para abalar a base igualitária comum na qual essa categoria funda-se. Enquanto Fraser (2000; 2003) procurou, mais recentemente, tematizar o reconhecimento por meio de um modelo de status, Taylor (1994a) manteve-se fiel a uma abordagem com contornos mais identitários.

No modelo de status, o reconhecimento é fruto de padrões institucionalizados de interação social que, supostamente, deveriam permitir a todos participarem da vida social de forma igualitária. Nesta perspectiva, as lutas sociais contemporâneas guiariam-se pelo padrão deontológico da participação paritária, tido como uma "receita para o diálogo e a participação democrática" (BAUMAN, 2001, p.146). Para alcançá-lo, duas condições devem ser observadas: objetiva e intersubjetiva. A primeira engloba uma distribuição de recursos materiais que seja suficientemente equânime a ponto de assegurar independência e voz aos participantes, enquanto a outra requer dos modelos institucionalizados de valores culturais que estes expressem o mesmo respeito a todos os participantes. Enquanto a primeira enfoca preocupações tradicionalmente associadas à teoria da justiça distributiva, em especial as questões relativas à estrutura econômica da sociedade e aos diferenciais de classe, a segunda centra-se em preocupações recentemente ressaltadas pela filosofia do reconhecimento, em especial as questões relacionadas à ordem de status, mediada por instituições que perpetuam padrões culturalmente definidos como mais ou menos apreciáveis. Fraser (2002) faz questão de ressaltar que nenhuma dessas condições é um efeito epifenomenal da outra. Pelo contrário, cada qual guarda relativa independência, visto que se trata de duas diferentes ordens de subordinação existentes nas sociedades capitalistas: estrutura de classe, que impede a alguns o acesso aos recursos necessários para que interajam como pares; e hierarquia de status, que nega 
aos indivíduos os padrões culturais de reconhecimento que lhes possibilitariam uma participação igualitária. Com isso, a teoria de Fraser, conforme afirma Silva (2005), tem o mérito de recuperar para a agenda teórica e política a noção de redistribuição, bem como apontar caminhos para uma reelaboração crítica do conceito de cidadania social. Resumindo, pode-se dizer que interessa à autora, como destaca Souza (2003, p.38), construir subsídios conceituais que lhe permitam ir além de uma descrição fenomenológica das situações que conferem ou não reconhecimento, especialmente no seu sentido "atitudinal", no intuito de desvelar o ancoramento institucional que lhe outorga boa parte de sua opacidade e eficácia, permitindo que "nossa vida cotidiana seja perpassada por distinções, hierarquias e princípios classificatórios não percebidos enquanto tais”.

Taylor (1994a), entretanto, chama a atenção para um ponto que não foi devidamente elucidado acima e que diz respeito à dimensão não-jurídica de levar-se o outro em consideração, denominada pelo autor de respeito atitudinal, o qual tem de estar disseminado de forma efetiva na sociedade para que se possa vislumbrar concretamente a dimensão jurídica da cidadania e da igualdade garantida pela lei. Tendo como referência a discussão sobre a emergência da noção de dignidade, a qual se deu na passagem do ancien régime para a modernidade, Taylor afirma que enquanto a noção de honra esteve comprometida com as idéias de hierarquia e exclusividade e desempenhou um papel importante nos processos de distinção social, a dignidade pressupôs um reconhecimento universal entre iguais. É esta noção universalista de dignidade que acabou por ensejar a institucionalização da igualdade consubstanciada na noção de cidadania. Esse processo detonou dois movimentos quase de modo sequiencial. À difusão da universalização de direitos, em um primeiro momento, seguiram-se demandas pelo reconhecimento de uma identidade autêntica, no plano individual e coletivo. Se o princípio da dignidade relaciona-se à justiça redistributiva e à titularidade de direitos inerentes à condição de cidadania, o princípio da autenticidade relaciona-se a um ideal que ganha força moral no pensamento ocidental e legitima-se na idéia de que cada um deve ter assegurado a plena expressão de sua individualidade, calcada justamente no direito de todos a terem suas diferenças valorizadas (TAYLOR, 1994b). 
As considerações de Taylor sobre a dignidade, entendida como uma base valorativa sobre a qual se apóia a construção de um reconhecimento em moldes igualitários e sobre a qual se assenta a cidadania, remetem à relação que se estabelece entre a eficácia legal da regra de igualdade e o fato de que esta eficácia só será socialmente reconhecida se a percepção da igualdade na dimensão da vida cotidiana estiver efetivamente internalizada. Como destaca Souza (2004, p.87),

(...) esse gigantesco processo histórico homogeneizador, aprofundado posteriormente pelas conquistas sociais e políticas da própria classe trabalhadora, pode ser entendido como um processo em larga escala de aprendizado moral e político de profundas consequiências. Evidentemente, não equalizou as classes sociais em todas as esferas da vida, mas sem dúvida generalizou e expandiu concepções fundamentais em torno do ideal de igualdade para as esferas civis, políticas e sociais, como analisou Marshall em seu célebre texto.

Em consonância com a idéia de abarcar as recentes transformações culturais sem perder de vista a histórica ênfase igualitária, alguns grupos têm lançado mão de recursos identitários que possuam um apelo e uma eficácia perante a sociedade para que esta possa reconhecer neles o direito de existirem enquanto cidadãos iguais aos demais membros da sociedade, a despeito de tais direitos lhes serem assegurados legalmente. Esta perspectiva é condizente com o que Neves (2002, p.214) afirma tratar-se de reivindicações pela "cidadania simbólica", em função de sua capacidade de evitar a naturalização das desigualdades sociais e das diferenças culturais a que estão sujeitos os "não-cidadãos", os quais são assim chamados "não porque seus direitos não são respeitados, (...) mas porque não são vistos como portadores de direitos". Abordar o reconhecimento como uma das dimensões da cidadania permite, portanto, não desvinculá-lo das lutas sociais por igualdade nem das relações de poder em vigor na sociedade (SILVA, 2000). Em contrapartida, inseri-lo na esfera da cidadania significa dar a esta última um status que desloca a análise do que é instituído legalmente a todos de forma igualitária para enfocar o que, de fato, é incorporado às práticas e às relações sociais. 
Assim, de acordo com a argumentação desenvolvida nesta seção, observa-se uma relação teórica latente entre as noções de reconhecimento social e de cidadania, especialmente pelo fato de que ambas se sustentam, nas suas formulações originais, sobre um princípio de dignidade/ igualdade compartilhado. Em que medida esta relação pode ser universalizada ou, ao contrário, necessita ser reelaborada em função das especificidades socioeconômicas e culturais de configurações sociais distintas é o foco das próximas seções.

\section{Problematizando o reconhecimento na "moderni- dade periférica"}

Conforme observado na seção anterior, a vinculação entre reconhecimento e igualdade ancora-se em um contexto no qual foram instituídos, com significativo grau de abrangência, princípios igualitários. Estes princípios incidem na definição dos parâmetros sociais de (in)justiça e, assim, integram a economia moral da população, ou seja, as concepções de "justiça social, direitos e obrigações, reciprocidade” (THOMPSON, 1998, p.259) através das quais os diversos atores avaliam suas posições relativas e buscam o reconhecimento social de sua dignidade e de sua autenticidade.

Transposta para o contexto brasileiro, no entanto, a perspectiva teórica do reconhecimento social depara-se com uma configuração social bastante diferenciada, na qual a desigualdade se constitui em "elemento estruturante da sociabilidade, estando presente em cada momento das relações sociais” (CARDOSO, 2004, p.136). Quais as implicações desta desigualdade, reiteradamente destacada por diversos analistas como elemento estruturante da realidade social brasileira, para os processos através dos quais constrói-se o reconhecimento social no país?

Talvez o exemplo mais paradigmático das implicações da desigualdade expresse-se na forma como a cidadania constituiuse e institucionalizou-se no país. Diferentemente da formulação de Marshall (1967), que apreende a cidadania como um estatuto inerentemente universalizado e igualitário, a cidadania à brasi- 
leira, não obstante constitua-se sobre um princípio formal de igualdade, instituiu-se, de fato, como estatuto diferenciador vinculado à inserção dos indivíduos em um sistema de estratificação ocupacional, ficando sujeita a uma lógica de "igualdade dos iguais" (NEVES, 2002, p.209). Esta associação entre cidadania e desigualdade, que subverte o sentido igualitário original do conceito de cidadania, foi apreendida de forma pioneira por Santos (1987, p.68) através da sua definição de "cidadania regulada", na qual "[a] cidadania está embutida na profissão e os direitos do cidadão restringem-se aos direitos do lugar que ocupa no processo produtivo, tal como reconhecido por lei”.

Esse processo histórico levou à cristalização do que Neves (2002, p.206) denomina de uma "cidadania dual", que se expressa pela incorporação seletiva da população ao seu usufruto. Tal configuração contribuiu para a produção de uma distinção entre cidadãos supostamente iguais em função da posição diferenciada que ocupam no gradiente hierárquico de direitos e deveres. Sem referência a um princípio de igualdade incorporado e institucionalizado, tal distinção depende da produção e/ou manutenção de uma correlação de forças que possibilite àqueles que a almejam instituí-la como uma situação de fato ou institucionalizá-la como uma situação de direito ${ }^{1}$.

Frente à peculiaridade deste contexto, o artigo problematiza um aspecto que foi pouco explorado pelas ciências sociais brasileiras: a forma como a desigualdade insere-se e é reproduzida nas próprias ações coletivas dos setores subalternos da sociedade brasileira na sua busca por reconhecimento social. Para analisar esse problema, parte-se do argumento de Kerstenetzky (2003, p.132), segundo o qual: "quando as desigualdades socioeconômicas são 'duráveis' e elevadas é bem plausível que se repliquem no interior da vida associativa, bem como entre grupos organizados e não organizados". Mais especificamente, então, este artigo estabelece

1 Este aspecto é claramente ilustrado pelo recurso constante, entre setores da elite brasileira, ao discurso dos "direitos adquiridos" para a justificação do acesso particularista e não-universalizável a determinados bens públicos (salário, crédito, isenção fiscal, aposentadoria, etc.), que, dada sua conformação histórica, se constituem em privilégios. 
a hipótese de que, em contextos sociais nos quais imperam altos índices de desigualdade e inexiste um princípio de igualdade orientando a ação dos agentes e das instituições sociais, a busca por reconhecimento social tende a orientar-se não pela luta para ser reconhecido como integrante de uma comunidade de iguais - que, de fato, inexiste -, mas, ao contrário, pela luta para marcar uma distinção que possibilite usufruir os ganhos materiais e simbólicos associados a esta posição diferenciada.

Particularmente no que se refere às ações coletivas dos setores subalternos, haveria uma tendência à ambigüidade: por um lado, observa-se uma crítica às desigualdades e injustiças que os colocam em posição de subalternidade; por outro lado, identifica-se um esforço para destacar determinadas características distintivas - organização, potencial de ação direta, "consciência”, acesso a mediadores, inserção institucional, capacidade propositiva etc. - que demarcariam uma "superioridade" em relação a outros grupos subalternos e, assim, justificariam um acesso diferenciado a determinados bens materiais e/ou simbólicos. $\mathrm{O}$ argumento explorado neste trabalho, portanto, é o de que as lutas por reconhecimento, no contexto da "modernidade periférica", no qual a naturalização da desigualdade social constitui-se em um princípio estruturante básico que perfaz sua singularidade, podem acabar traduzindo-se em lutas por distinção.

Duas ressalvas devem ser destacadas em relação a este argumento, no sentido de evitar uma interpretação equivocada. Por um lado, ele não implica na aceitação da idéia de que a desigualdade e as estratégias de distinção teriam sido superadas nos ditos países centrais. Ao contrário, como ilustra o trabalho de Bourdieu (1984), estes são aspectos-chave das relações entre os agentes e as classes sociais naqueles países. No entanto, o que se destaca é o fato de que, naqueles países, a desigualdade e a distinção tendem a ser limitadas por princípios igualitários constitutivos da economia moral de suas populações, os quais conferem "viabilidade política" e "plausibilidade simbólica" à noção moderna de cidadania enquanto estatuto universal, a despeito do fato de que profundas transformações que se deram nas últimas décadas têm configurado, mesmo em países centrais, "um panorama que encerra certa ironia 
histórica: o reconhecimento da diferença, porém sem equiidade" (LAVALLE, 2003, p.75-76). ${ }^{2}$

Por outro lado, este argumento não objetiva nenhum tipo de desqualificação ou condenação das ações coletivas dos setores subalternos, como é comum na tradição elitista que marca o pensamento social e político brasileiro (PERLMAN, 1981; SADER; PAOLI, 1986; ZALUAR, 1994), a qual tende a responsabilizar os dominados pela (re)produção de sua dominação, mas sim mostrar como estas ações, independentemente da intencionalidade dos seus protagonistas ${ }^{3}$, podem estar (re)produzindo as desigualdades contra as quais se mobilizam, conspirando, assim, contra a superação das mesmas.

\section{A experiência de organização dos catadores sob a perspectiva do reconhecimento social ${ }^{4}$}

O propósito desta seção é tomar como objeto de análise um processo de organização coletiva de catadores de materiais recicláveis, no sentido de mostrar as tensões e ambiguiidades que marcam

2 A questão da imigração assume um caráter profundamente tensionador da ordem social nos países centrais, entre outros fatores, por colocar em xeque os princípios igualitários e universalistas que, em maior ou menor grau, compunham a economia moral de suas populações.

3 Esta ênfase no caráter não-intencional, mas prático, das formas como se manifestam as desigualdades encontra-se em Souza (2004, p.92): "Não se trata de intencionalidade. Nenhum brasileiro europeizado de classe média confessaria, em sã consciência, que considera seus compatriotas das classes baixas não-europeizadas 'subgente'. Grande parte dessas pessoas votam em partidos de esquerda e participam de campanhas contra a fome e coisas do gênero. A dimensão aqui é objetiva, subliminar, implícita e não transparente. Ademais, ela não precisa ser mediada pela linguagem nem simbolicamente articulada; implica, como a idéia de habitus em Bourdieu, toda uma visão de mundo e uma hierarquia moral que se sedimentam e se mostram como signo social de forma imperceptível a partir de signos sociais aparentemente sem importância, como, por exemplo, a inclinação respeitosa e inconsciente do indivíduo 'inferior' na escala social quando encontra com um 'superior', pela tonalidade da voz mais do que pelo que é dito, etc. $\mathrm{O}$ que existe aqui são acordos e consensos sociais mudos e subliminares, mas por isso mesmo tanto mais eficazes, que articulam, como que por meio de fios invisíveis, solidariedades e preconceitos arraigados".

4 Esta seção resgata uma discussão prévia feita em Michelotti (2006), extraindolhe novos contornos teóricos. 
as lutas por reconhecimento social desta categoria em um contexto de extrema desigualdade. Para desenvolver esta análise nos marcos limitados deste artigo, optou-se por abordar, além de um rápido histórico da organização dos catadores no estado do Rio Grande do Sul, aspectos nos quais aquelas tensões e ambiguiidades ganham destaque, indicando os dilemas das lutas por reconhecimento social na "modernidade periférica".

O processo de organização dos catadores, pelo menos do ponto de vista da constituição de entidades formalizadas, é relativamente recente no Brasil. A partir dos anos noventa, verificou-se um incremento significativo na adesão de catadores de rua a processos de organização coletiva, facilitado pelo contato com entidades religiosas, pela preocupação ambiental crescente em diversas esferas governamentais e, também, pelo surgimento e atuação de várias entidades da sociedade civil que assessoraram projetos, resultando na fundação de muitas das atuais associações e cooperativas de catadores.

No caso de Porto Alegre, em particular, onde tem origem o processo de organização que é discutido aqui, o desencadeamento desse processo foi, em grande medida, resultado da ação de agentes religiosos ligados às comunidades eclesiais de base, que desempenharam o papel de induzi-lo com o intuito de dar visibilidade social aos catadores, bem como gerar trabalho e renda para a categoria. Em um segundo momento, essas experiências de organização deslocaram-se da tutela exclusiva dos agentes religiosos para abranger os técnicos governamentais quando, a partir de 1989, a "Frente Popular" - coligação de partidos liderada pelo PT - assume a Prefeitura de Porto Alegre e incorpora a proposta de dar continuidade ao processo de organização mediante a criação de um "sistema de gerenciamento integrado de resíduos sólidos", sob responsabilidade do Departamento Municipal de Limpeza Urbana (DMLU), que passou a interferir diretamente nos rumos desse processo. Mesmo sendo controverso no que se refere à forma como integrou a coleta seletiva dos materiais recicláveis às chamadas Unidades de Triagem (UTs), edificadas pelo poder público, tendo a coleta efetuada pelos catadores de rua sido considerada oficialmente irregular e "desviante", o êxito obtido pelo programa ultrapassou as fronteiras municipais e influenciou experiências 
semelhantes em todo o país, além de render ao governo municipal visibilidade em âmbito internacional.

No início desse processo de organização, os catadores mantiveram relações com os agentes externos de forma isolada e eminentemente para tratar de assuntos ligados à situação de cada UT em particular. Com isso, foi recorrente a instalação de relações personalistas, na qual a proximidade pessoal significou ganhos ou favores atendidos, os quais foram concebidos, para usar uma expressão de Neves (2002, p.210), "não como 'direitos', mas como 'dádivas', ou meras formalidades para uso midiático”. Já a segunda metade dos anos noventa testemunhou o início de uma aliança entre as associações já constituídas, que resultou na criação de um fórum de discussão que articulou catadores e agentes externos (órgãos privados, universidades e demais entidades da sociedade civil organizada) rumo a um processo que culminou, em 1998, com a fundação de uma entidade formalizada em termos jurídicos - uma federação -, cuja abrangência estadual permitiu uma primeira articulação entre as associações que estivessem filiadas a ela.

O propósito maior com a fundação da federação foi o de suprir a falta de uma instância jurídica que garantisse a gestão comum dos recursos econômicos que estavam sendo destinados às associações, com vistas a investir na construção de diversas micro-usinas de reciclagem de plásticos em todo o estado, de forma que "precisava um pouco este instrumento para viabilizar essa questão mais empreendedora" (R., sexo masculino, 49 anos, $3^{\circ}$ grau incompleto, Federação), porque "somente o catador como pessoa não poderia, então precisaria ter essa entidade" (A., sexo masculino, 25 anos, 1 o grau incompleto, Movimento). Outro objetivo importante consistia em propiciar aos associados atividades de formação e capacitação.

O caráter autônomo de tal processo pode, todavia, ser questionado se considerados os laços de dependência estabelecidos com os agentes externos e, também, no que diz respeito à participação dos catadores, os quais ainda não pareciam o estar protagonizando. Afinal, segundo comenta uma das entrevistadas, que foi sua coordenadora geral durante a gestão 2002-05, a fundação da federação deu-se, basicamente, em decorrência da presença de outros segmentos sociais: 
"Eu costumo dizer que a Federação ela não surgiu da idéia dos catadores (...) ela não foi, vamos dizer assim, pensada pelos catadores. E por que eu digo isso? Porque, na verdade, os catadores vêem a Federação como se tivesse num outro patamar, que não fosse uma coisa deles, então, na verdade assim, se o processo fosse construído de baixo para cima, com a decisão, com os custos que iria ter essa entidade, o tempo, né, os objetivos, a missão, e tudo, né, os catadores se apropriariam disso, mas como foi uma demanda de cima para baixo..." (E., sexo feminino, 36 anos, $1^{0}$ grau incompleto, Federação).

A partir de 2000, a Federação insere-se no processo de construção de um congresso nacional de catadores, cuja mobilização que o antecedeu propiciou as condições organizacionais necessárias para que, durante o evento, fosse aprovada a idéia de criação de um movimento nacional, devido ao fato de que "a luta que vinha mais adiante não é uma luta institucional, mas uma luta social, que era de valorização e reconhecimento dos catadores" (A.). Segundo R., "a Federação, ela participou da fundação do Movimento, fez toda a articulação, foi uma das entidades que fez a articulação para que acontecesse o congresso e dali surgiu o Movimento".

Durante a realização do Congresso, de 4 a 6 de junho de 2001, em Brasília, houve grande mobilização por parte das lideranças em torno da aquisição de um estatuto legal para a sua atividade, da inclusão dos catadores em programas municipais de coleta seletiva, da criação de linhas de financiamento para suas associações e cooperativas e de mecanismos tributários para incentivar a indústria nacional da reciclagem (GONÇALVES, 2003). Visto como desdobramento de todo um processo anterior de organização, o congresso prestou-se a ser um momento de reivindicação especialmente para aqueles que trabalhavam de forma associativa, bem como de incentivo para que o processo de reciclagem passasse a ser desenvolvido em todo o país, prioritariamente, por empresas sociais de catadores. Ao privilegiar legislações que instituíssem a ocupação de catador e garantissem a inclusão dos catadores em sistemas de coleta seletiva, tais demandas acabavam por favorecer o estabelecimento de um vínculo entre os catadores e o trabalho em associações ou cooperativas como um meio de atingir o reconhecimento social de sua ocupação. Ou seja, observa-se aqui a reprodução do padrão tradicional de acesso à 
"cidadania regulada" através da regulamentação ocupacional, o qual permitiria àqueles capazes de usufruírem da nova identidade ocupacional de catador (em princípio, os que se organizassem em associações e cooperativas) o gozo de determinados direitos (previdenciários e trabalhistas, particularmente) do qual se encontravam excluídos até o momento.

Um dos aspectos marcantes desse processo de regulamentação ocupacional foi a disputa em torno de qual denominação utilizar: catador ou reciclador. Subjacente a esta disputa em torno da forma de denominação da nova ocupação, observa-se uma divergência sobre o modo como almejam ser reconhecidos, a qual se expressa na tensão entre uma denominação mais inclusiva - catador - e uma denominação mais restritiva - reciclador. G. (sexo masculino, 30 anos, $2^{\circ}$ grau incompleto, Movimento) afirma que a opção por incluir o termo catador na Classificação Brasileira de Ocupações havia se dado para evitar o que considera um "contrabando ideológico" da parte de empresários e também de catadores "que batem no peito que são recicladores", mas que possuem uma "consciência de classe mais empresarial". Para ele, o estímulo ao uso do termo "reciclador" tende a inculcar nos trabalhadores a idéia de que podem deixar de se verem como uma "massa que está excluída" para tornarem-se, individualmente, "empresários do lixo (...) elevando a consciência do catador ao nível do empresariado". Ser catador ganha sentido para o Movimento desde que ele "se entenda como parte de uma classe" e isso, segundo algumas lideranças do Movimento, é visível mesmo corporalmente: "o catador sabe quem é catador, olha na cara, olha nas mãos, olha, sabe, no estilo de quem mete a mão no trabalho, isso está bem marcado mesmo" (G.); "nós nascemos no seio da pobreza, no seio da miséria, nós temos isso dentro do nosso corpo, nosso organismo é formado disso, e nós temos isso também desde os nossos antepassados, que vieram dos escravos, dos índios, que eram explorados aqui no nosso país" (A. $)^{5}$.

5 Estes depoimentos, destacando a dimensão corporal das identidades e das desigualdades sociais, expressam de forma surpreendente clara as idéias formuladas por Souza (2003, p. 46), a partir de sua leitura da obra de Bourdieu: "Os nossos corpos são (...), na sua forma, dimensão, apresentação etc., a mais tangível manifestação social de nós mesmos. Nossos hábitos alimentares mol- 
No entanto, as limitações desta conquista de regulamentação ocupacional, no sentido da garantia de um efetivo reconhecimento social para o conjunto de um segmento social altamente estigmatizado, foram percebidas com clareza por algumas lideranças. R., por exemplo, argumentou que, em termos práticos, a regulamentação da ocupação não se traduziu em um reconhecimento social da ocupação, visto que, para ele, tal condição "não se dá por decreto, o reconhecimento de uma profissão, de uma atividade, se dá pelo trabalho que você consegue fazer com aquela população para enxergar a importância dela. Nada acontece por decreto!”. Neste sentido, A. acrescenta que "se a gente não se reconhecer primeiro enquanto pessoa, enquanto cidadão, ninguém vai reconhecer", afinal, só essa condição legal não garante que "agora tu tens mais livre acesso dentro da sociedade".

Frente a este poderoso estigma que afeta os catadores, o qual chega a limitar os efeitos da regulamentação ocupacional como instrumento de reconhecimento social, o argumento ecológico parece ser um recurso discursivo com crescente centralidade na busca de dignidade e aceitabilidade da figura do catador. A partir deste argumento, o catador não é mais encarado como um baderneiro ou indigente, mas um prestador de serviços à causa ambiental, devidamente regulamentado, o que o torna um autêntico "agente ambiental", capaz, inclusive, de contribuir, segundo consta em um guia produzido pelo Fórum Nacional Lixo e Cidadania em parceria com a UNICEF, "para amenizar os efeitos negativos do nosso desperdício” (ABREU, 2001, p.19).

É particularmente notável a necessidade de legitimar os catadores a partir do argumento que constituem uma categoria profissional cujo serviço prestado possui um caráter de grande utilidade pública, passível de ser reconhecido pela "importância

dam nossa figura, enquanto nossa cultura e socialização pré-formam todas as nossas manifestações expressivas em gestos, escolha de vestuário, corte de cabelo, forma de andar e falar, transformando o conjunto de nossas expressões visíveis em sinais sociais. É com base nesses sinais visíveis que classificamos as pessoas e grupos sociais e lhes atribuímos prestígio ou desprezo. (...) Desse modo, o corpo funciona como uma espécie de 'operador analógico' das hierarquias prevalecentes no mundo social". 
ambiental" que lhe é intrínseca, o que mais facilmente faz com que a sociedade sinta "a necessidade de valorizar a sua profissão" (ABREU, 2001, p.34-35). Em uma entrevista concedida na presença de uma representante de uma ONG francesa que oferece apoio financeiro para projetos, o presidente da associação de moradores da chamada Vila dos Papeleiros, em Porto Alegre, declara sobre o lugar onde ele e mais cerca de 212 famílias residem: "Moramos num lugar onde um cachorro não quer viver. Mas temos utilidade. Quanto mais papel apanharmos, menos árvores vão ser derrubadas" (O SUOR, 2003, p.33). Ou seja, o reconhecimento social dos catadores não estaria associado ao compartilhamento de uma condição de cidadãos - e, no limite, de seres humanos -, mas sim ao fato, a ser afirmado e demonstrado, de que podem desempenhar alguma tarefa "útil" para a sociedade.

A força deste argumento expressa-se nos depoimentos apresentados tanto por lideranças da Federação quanto do Movimento. Neste sentido, G. afirma que a luta do Movimento é pela "valorização e reconhecimento do trabalho histórico do catador de material reciclável na luta pela preservação do meio ambiente". Em relação a esta questão, assim também se expressa A.,

"o nosso trabalho é de que? É de triar esse material, de tirar esse material que iria para a natureza, nós triamos e demos um outro...nós fizemos um outro encaminhamento. Não aquele do aterro sanitário, onde vai acumulando grandes quantidades que vai, por fim, poluindo o meio ambiente, destruindo a natureza. Nós fizemos a inversão desse trabalho. Então é nessa parte que nós temos que ser valorizados".

Em entrevista com a ex-1a secretária e atual coordenadora da Federação, foi-lhe pedido que qualificasse as motivações que estariam por trás da demanda de que a sociedade reconhecesse o catador, ao que ela prontamente respondeu:

"Que nós prestamos um grande serviço para o meio ambiente! Que nós prestamos um grande serviço para a comunidade. Que o nosso trabalho seja reconhecido, não como um simples lixeiro, mas simplesmente como tra-ba-lha-dor do meio ambiente! Seja um idealizador de uma categoria que trabalha para defender e preservar a natureza, né!" (B., sexo femino, 59 anos, $2^{\mathrm{o}}$ grau incompleto, Federação). 
Esta desqualificação social dos catadores é, em certa medida, incorporada e re-significada nos próprios discursos de seus representantes, que estabelecem duas formas de distinção que segmentariam o universo dos catadores em grupos marcados por características e, particularmente, valores distintos. Estas formas de distinção separariam: os organizados e os não-organizados; e, entre os organizados, os militantes e os empreendedores.

A distinção entre catadores organizados e não-organizados, reiteradamente destacada por reportagens e manifestações de integrantes de órgãos públicos ligados às políticas de reciclagem de resíduos (CAMPANI, 2002; MARIANO, 2003; SELISTER, 2005; ZERO HORA, 2005) ${ }^{6}$, também pode ser encontrada entre as lideranças da Federação e do Movimento, havendo, no entanto, uma disputa entre estes sobre o que significa "ser organizado". Para a Federação, que nasce exatamente da união de associações e cooperativas de reciclagem, a organização se expressaria na constituição destas estruturas formais, as quais possibilitariam uma demarcação clara dos recicladores em relação aos catadores que atuam de forma nãoorganizada e externa às UTs. Para o Movimento, diferentemente, a organização expressa-se como inserção no próprio Movimento, na incorporação de suas propostas e discursos, na identificação com seus princípios ético-políticos e na participação em suas ações. Ou seja, a organização expressar-se-ia menos na inserção em algum empreendimento formal de reciclagem e mais na "conversão" dos catadores, atuando coletivamente ou não, ao Movimento. Para G., esta visão dicotomizada, que o próprio poder público insiste em

6 Da parte do poder público local, representando pelo DMLU, há um discurso que enaltece o caráter associativo como um meio de assegurar aos catadores condições dignas de trabalho para que "deix[e]m de representar um problema e pass[e]m a ser uma solução social” (CAMPANI, 2002) em detrimento à atividade executada pelos não-organizados na forma de uma catação clandestina que age no sentido de "desviar" material da coleta seletiva tida como oficial (SILVEIRA, 2002). Na cidade do Rio de Janeiro, o quadro pouco se altera, visto que segundo uma classificação que consta nos relatórios da Companhia Municipal de Limpeza Urbana, e citada em Carmo; Oliveira \& Migueles (2004), há quatro diferentes tipos de catadores, sendo que um deles é denominado de "catador predatório de rua", cuja atividade ocorre de modo antecipado à coleta oficial, gerando "distúrbios" para a condução do trabalho pelo poder público e supostamente causando prejuízos aos catadores organizados. 
perpetuar, condiz com a "cisão" que se quer estabelecer entre catadores associados e de rua através do uso dos termos "reciclador" e "catador", os quais conteriam significados ideológicos distintos, visto que o primeiro significa:

"que nós também podemos ser empresários do lixo, e ao sermos empresários do lixo, nós deixamos de ser aquele povo que está nas ruas e nos lixões e aí criamos uma cisão, uma ruptura entre os que têm privilégios de ter talvez alguma estrutura de apoio do poder público ou das empresas, e aquela massa que está nas ruas. Por isso que nós temos uma ruptura entre os que se chamam recicladores, e que tem um galpãozinho, um local de triagem e os que se chamam catadores, que é a massa que está excluída, né".

Estas diferentes percepções do que significa organização e os conflitos daí decorrentes são claramente perceptíveis nos depoimentos das lideranças entrevistadas. Segundo A., a ruptura entre o Movimento e a Federação deu-se muito em decorrência desta última ter se restringido à organização dos catadores que estavam em "associações já formadas" - porque, na visão de R., uma das lideranças da Federação, "nós entendemos que catador individual não tem futuro" -, enquanto o Movimento teria se proposto a "organizar os catadores na sua essência” (G.), o que incluía pensar uma estrutura organizacional, não necessariamente de caráter formal, para aqueles que optassem por trabalhar nas ruas ou ainda para aqueles que não tivessem outra opção senão permanecer nelas, de forma que sempre se almejou estender as conquistas a toda a categoria, independentemente da existência de um vínculo associativo.

"o fato é que a maioria, a massa, os 99,9\% da população catadora vive de catar nas ruas ou nos lixões ainda em condições mais básicas, na parte mais inicial do ciclo, inclusive, catando e entregando para sucateiros logo adiante, intermediários. O Movimento vem para reconhecer (...) para buscar conquistas para esse setor, sem confundir com o setor reciclador" (G.).

No entanto, mesmo que haja uma relação conturbada entre o Movimento e certos órgãos públicos - como o DMLU, por exemplo - , na medida em que aquele tende a confrontar as tentativas governamentais de separação entre reciclador e catador, a importância de se ter parcerias com os sistemas oficiais de coleta seletiva não 
é negada pelo Movimento, sendo expressa, inclusive, no relatório de um encontro de militantes, que menciona que "a mobilização precisa ser feita de forma organizada junto com o poder público, porque só assim a sociedade percebe que o catador é um trabalhador realmente inserido na economia e na política" (RELATÓRIO, 2006). A reivindicação de que os catadores sejam reconhecidos como profissionais capazes de empreenderem uma ação conjunta com o poder público, "visando à estruturação do trabalho de coleta, separação e preparação de materiais recicláveis para fins de encaminhamento para reciclagem", é a base de um convênio proposto pelo Movimento para a inclusão tanto dos catadores de rua quanto dos que são "organizados junto às entidades já existentes", desde que, como argumenta V. (sexo masculino, 49 anos, $1^{\circ}$ grau incompleto, Movimento), trate-se de militantes que sigam "as regras do Movimento". Ou seja, aqui se observa que, mesmo que a distinção entre reciclador e catador seja rejeitada enfaticamente pelo Movimento - incluindo, assim, os catadores que trabalham em associações e cooperativas -, este estabelece uma outra distinção, agora entre os catadores organizados de acordo com as "as regras do Movimento" e os outros catadores, buscando instituir um convênio com o poder público que garanta, principalmente aos primeiros, o acesso aos materiais recicláveis.

Como desdobramento desta distinção entre catadores organizados e não-organizados, observa-se uma segunda distinção - e disputa - entre catadores "militantes" e "empreendedores". Esta segunda distinção está diretamente relacionada às posições diferenciadas da Federação e do Movimento sobre o significado do que é ser organizado, observado anteriormente, e sobre as estratégias de reconhecimento social a serem empreendidas pelos catadores para romper com sua condição subalterna na sociedade.

Para grande parte das lideranças do Movimento, ainda faltaria aos catadores, de modo geral, uma "consciência de classe" e uma postura de "militância" que lhes possibilitasse enxergar a situação de exploração na qual se encontram e da qual somente terão condições de sair mediante uma tomada de consciência que fortaleça a organização coletiva do Movimento. A ênfase dada ao trabalho de militância acaba, contudo, se convertendo em um distanciamento 
real entre os dirigentes - tidos como mais conscientes - e o restante dos catadores, cujo nivelamento demanda que estes últimos passem, primeiro, por um processo de formação fundamentalmente de caráter político para que venham a conhecer "os princípios do Movimento, a base de acordo e tudo mais" (A.). A diferenciação assim estabelecida entre os catadores, como demonstra a fala de V., chega até mesmo a demarcar fronteiras acerca de quem são os catadores que merecem alguma forma de solidariedade e reconhecimento social:

"conhecer as lideranças de cada lugar, de cada vila, pegando as lideranças, pegando pessoas que tenham a vocação pra coordenar alguma organização, algum povo que está atirado em algum canto, né, então, ele está pegando essas lideranças e com essas lideranças está fazendo uma formação (...). Uma das prioridades do Movimento é selecionar e capacitar o pessoal que vai fazer parte dele, e eu acho que isso é uma coisa importante (...) tem que primeiro organizar o povo e uniformizar o povo pra se destacar da pessoa que não é organizada, então aí (...) aquele pessoal é do Movimento, vamos ajudar porque o pessoal é o pessoal que trabalha, pessoal que tem dignidade, pessoal de respeito, pessoal que para pra conversar, entendeu!".

Assim, o catador é reconhecido pelo Movimento como "militante" a partir do momento em que dedica parte de seu tempo à "formação política" (T., sexo masculino, 34 anos, 1 o grau incompleto, Movimento), estabelece um comprometimento pessoal com o Movimento, subordina-se aos ideais calcados nas bases de acordo existentes, conquista laços de confiança e de solidariedade com os "militantes de cada base [orgânica]" (C., sexo masculino, 18 anos, $1^{\text {o }}$ grau completo, Movimento) e está pronto para atuar nas mobilizações de reivindicação - ação direta - organizadas pelas lideranças, sendo que estas ficam responsáveis por sustentarem um intenso trabalho de articulação que extrapola o âmbito restrito das associações, além de prepararem-se para lidar com situações tensas de negociação junto às mais diversas instâncias, em especial quando envolvem agentes do poder público, considerado um "adversário muito forte" (G.).

Em contrapartida, para as lideranças da Federação, vinculadas à denominação de reciclador como recurso de distinção em relação aos catadores (não organizados em associações ou cooperativas), o reconhecimento social passa pela identificação como empre- 
endedores, a qual criaria possibilidades de acesso a recursos e oportunidades de expansão "em termos de negócio mesmo". Isto faz com que R., pertencente à associação apontada por Martins (2004, p.41) como sendo de "maior produtividade e melhores resultados econômico-financeiros no Rio Grande do Sul”, sugira aos seus colegas de trabalho que "não falem que vocês trabalham no lixo. Falem que vocês estão trabalhando na reciclagem! A partir daí, se as pessoas perguntarem 'O que é isso?', vocês terão condições de falar sobre o que fazem. Assim podem superar, aos poucos, o preconceito" (ADAMS, 2005, p.25).

Sob tal perspectiva, os cursos de formação de lideranças realizados pela Federação têm objetivado instrumentalizar os recicladores para o trabalho associativo e/ou cooperativo, abordando assuntos que vão desde a criação destas entidades, confecção de estatuto e regimento interno, obtenção de licenciamento de acordo com os padrões de conformidade ambiental que constam nas legislações vigentes, até formas de gerir o beneficiamento e a comercialização dos materiais. Tudo parece ser planejado para que o reciclador, aos moldes do que parece já acontecer com as lideranças, adquira "uma visão comercial, de mercado", porque senão vai perder espaço "frente à concorrência de empresários aí que cada vez mais estão tomando mais espaço junto aos municípios no gerenciamento de resíduos, vem com o pacote todo, com o poder econômico e tal” (R.).

Pode-se notar que o reciclador deve empreender uma atitude pragmática o suficiente para adaptar-se às exigências que forem necessárias para sobreviver a um mercado cada vez mais competitivo, interiorizar os valores e as normas sociais necessários para tanto e adquirir os recursos para que possa tornar-se autônomo a ponto de não precisar mais ser economicamente "ajudado", sendo que esta última situação, como conclui E., deriva do fato de o catador ainda ser "muito imediatista e aí não tem recurso para fazer um capital de giro". Para que o mercado da reciclagem seja assumido pelos recicladores, R. destaca que "o desafio é fortalecer o associativismo, e ele precisa se tornar mais empreendedor porque senão vai perder mesmo muito mais espaço".

Assim, mesmo contrapostos, observa-se que tanto os discursos das lideranças do Movimento quanto os das lideranças da 
Federação apontam para uma distinção que demarca o universo dos catadores/recicladores em segmentos dotados de valores diferenciados. No caso do Movimento, em direta articulação com um discurso que contesta a "ordem capitalista", o "militante" constitui-se na identidade valorizada e que deve ser produzida entre os catadores através das atividades de formação política do Movimento. Os catadores "sem consciência" ou, pior, os que se identificam enquanto recicladores são objeto de crítica e desqualificação, devendo, por isso, ser excluídos do acesso aos ganhos materiais e simbólicos obtidos pelo Movimento - com destaque nos últimos anos para recursos obtidos junto a diferentes esferas do governo federal. No caso da Federação, cujas lideranças tendem a buscar o reconhecimento através do êxito na inserção no mercado da reciclagem, o que se valoriza é a identidade de "empreendedor". Neste sentido, o empreendedorismo dos recicladores deveria ser fomentado através da apropriação, por parte deles, do conhecimento e da prática necessários ao sucesso em um mercado competitivo.

\section{Considerações finais}

Retomando os argumentos que orientaram este artigo, observa-se que a construção do reconhecimento social em contextos de desigualdades profundas, tal como o brasileiro, carece de princípios igualitários e universalistas nos quais possa ancorar sua justificação. Na falta deste fundamento igualitário, a acirrada disputa por recursos escassos entre os subalternos tende a produzir um contexto favorável à busca do reconhecimento através de estratégias de distinção, que destacam positivamente determinados atributos possuídos por alguns segmentos subalternos, ao mesmo tempo em que se (re)produz a desqualificação daqueles segmentos carentes desses atributos.

Especificamente no caso dos catadores, o que se pôde observar é mais a necessidade de organizarem-se em grupos que comunguem dos mesmos valores e produzirem argumentos que demonstrem a sua utilidade, para, assim, justificarem seu acesso a determinados bens e "direitos", do que sustentarem uma luta em grande medida, em vão - pelo reconhecimento do conjunto 
dos catadores enquanto brasileiros portadores dos direitos de cidadania e, no limite, iguais a todos os outros enquanto seres humanos. Assim, foram identificados diversos - e, em alguns casos, concorrentes - esforços de valorização dos catadores que apresentavam atributos que os distinguiam entre si e lhes ofertavam chances de reconhecimento social: atuação em organizações formalizadas legalmente e não nas ruas, utilidade ambiental, o estabelecimento de parcerias com o poder público, consciência militante e espírito empreendedor.

Frente a estes resultados da pesquisa, parece haver fundamentação empírica para a sustentação da hipótese, apresentada no início deste artigo, de que, em contextos sociais nos quais imperam altos índices de desigualdade e inexiste um princípio de igualdade socialmente instituído, o acesso ao reconhecimento social tende a construir-se pela luta para estabelecer uma distinção que possibilite usufruir os ganhos materiais e simbólicos associados a esta posição diferenciada. Ou seja, nestes contextos, as lutas por reconhecimento podem acabar traduzindo-se em lutas por distinção, na medida em que emergem de configurações sociais nas quais é importante distinguir-se para ser socialmente reconhecido e valorizado.

Demonstrou-se, assim, que, independentemente dos discursos e intencionalidades que orientam a atuação das organizações investigadas, as lutas por reconhecimento que elas desenvolvem são, em grande medida, marcadas por uma ambiguiidade: de um lado, a busca universalista do reconhecimento da dignidade e dos direitos de um segmento social submetido a condições extremas de carência e estigmatização; de outro, um esforço para distinguir-se de outros que se situam na mesma posição de subalternidade, estabelecendo uma intensa competição pelo acesso a determinados bens materiais e simbólicos escassos (articulação com atores políticos, recursos de programas governamentais, prestígio profissional, acesso a mediadores etc.). Esta lógica subverte a própria noção igualitária de direitos, no sentido de que estes passam a ser negociados nas mais diferentes instâncias, barganhados mediante um processo de organização coletiva que se torna condição para que se possa extraí-los de um suposto Estado de direito. A possibilidade de se ter "direitos" fica, assim, totalmente condicionada à capacidade que os 
agentes têm de organizarem-se e, principalmente, de distinguiremse pelo acesso a determinadas "vantagens". Considerando que as estratégias de distinção conspiram contra a ruptura radical com os princípios hierárquicos que fundamentam e legitimam a desigualdade social no país, na medida em que, se bem sucedidas, possibilitam, no máximo, o acesso de novos segmentos sociais aos privilégios associados a uma posição diferenciada e não universalizável, este artigo conclui que um dos entraves básicos à construção de uma efetiva cidadania no Brasil repousa na fragilidade com que princípios igualitários encontram-se sedimentados, mesmo entre os setores subalternos e as suas organizações. Ao contrário, entre nós, por diferentes critérios, a desigualdade tende a ser vivenciada como natural e, no limite, legítima.

Recebido em 7.7.2008 Aprovado em 11.11.2008

\section{Referências}

ABREU, M. de F. Do lixo à cidadania: estratégias para a ação. Brasília: UNICEF/Caixa Econômica Federal, 2001.

ADAMS, T. Vivendo e reciclando: Associação dos Recicladores de Dois Irmãos. São Leopoldo: Oikos, 2005.

BAUMAN, Z. The great war of recognition. Theory, Culture \& Society. V. 18. n. 2-3, p. 137-150, 2001.

BOURDIEU, P. A economia das trocas simbólicas. São Paulo: Perspectiva, 1974.

. Distinction. Cambridge: Harvard University, 1984.

CAMPANI, D. B. Gestão dos Resíduos de Porto Alegre. Palestra proferida durante o VI Seminário de Resíduos Sólidos, promovido pelo CONFEA/CREA - MG, 2002. Disponível em: < http://www.abessp.org.br/seminarioresiduos/2002/09.html> . Acesso em 26/10/05.

CARDOSO, A. M. Desigualdade, injustiça e legitimidade: uma investigação empírica sobre aspectos da sociabilidade brasileira. In: SCALON, C. (Org.). Imagens da desigualdade. Belo Horizonte: UFMG; Rio de Janeiro: IUPERJ/ FAPERJ, 2004. 
CARMO, M. S. do; OLIVEIRA, J. A. P. \& MIGUELES, C. P. A semântica do lixo, o estímulo à reciclagem e o trabalho dos catadores do Rio de Janeiro: Um estudo da relação entre significado e ação econômica. IntegrAção - A Revista Eletrônica do Terceiro Setor. FGV - EAESP, CETS. Ano VII, n. 34, 2004. Disponível em: < http://integracao.fgvsp. br/ano7/01/administrando.htm > . Acesso em: 06/09/05.

FRASER, N. Rethinking recognition. New Left Review. N. 3, p. 107-120, 2000.

. Redistribuição ou reconhecimento? Classe e status na sociedade contemporânea. Interseções. UERJ. Ano 4, n. 1, p. 7-32, 2002.

. Social Justice in the age of identity politics: Redistribution, recognition and participation. In: FRASER, N. \& HONNETH, A. Redistribution or recognition? A politicalphilosophical exchange. New York: Verso, 2003.

GONÇALVES, P. A reciclagem integradora dos aspectos ambientais, sociais e econômicos. Série Economia Solidária, n. 5. Rio de Janeiro: DP\&A: Fase, 2003.

KERSTENETZKY, C. L. Sobre associativismo, desigualdades e democracia. Revista Brasileira de Ciências Sociais. V.18, n. 53, p. 131-142, 2003.

LAVALLE, A. G. Cidadania, igualdade e diferença. Lua Nova. N. 59, p. 75-93, 2003.

MARIANO, N. A guerra pelo lixo reciclável. Zero Hora. Porto Alegre. Ano 40, n. 13.898, p. 32, 09 set., 2003.

MARSHALL, T. H. Cidadania, classe social e status. Rio de Janeiro: Zahar Editores, 1967.

MARTINS, C. H. B. Trabalhadores na reciclagem do lixo: dinâmicas econômicas, sócio-ambientais e políticas na perspectiva do empoderamento. 2004. Tese (Programa de Pós-Graduação em Sociologia) - Universidade Federal do Rio Grande do Sul, Porto Alegre.

MICHELOTTI, F. C. Catadores de "lixo que não é mais lixo": um estudo da dimensão do reconhecimento social a partir de sua experiência de organização coletiva no Rio Grande do Sul. 2006. Dissertação 
(Programa de Pós-Graduação em Sociologia) - Universidade Federal do Rio Grande do Sul, Porto Alegre.

NEVES, P. S. da C. Direitos humanos e cidadania simbólica no Brasil. p. 203-223. In: LYRA, R. P. (Org.). Direitos humanos: Os desafios do século XXI. Uma abordagem interdisciplinar. Brasília: Brasília Jurídica, 2002.

PERLMAN, J. O mito da marginalidade: favelas e política no Rio de Janeiro. 2. ed. Rio de Janeiro: Paz e Terra, 1981.

RELATÓRIO do Encontro dos 700. Artigos. Brasília. 14/04/2006. Disponível em: <http://www.mncr.org.br/download publicacaoonline.aspx?publicacao $=14042006132556$ Relatório $\% 20$ do\%20\%20Encontro\%20dos\%20700.pdf > . Acesso em: 21/04/06.

SADER, E. \& PAOLI, M. C. Sobre "classes populares" no pensamento sociológico brasileiro. In: CARDOSO, R. C. (Org.). A aventura antropológica: teoria e pesquisa. Rio de Janeiro: Paz e Terra, 1986.

SANTOS, W. G. Cidadania e justiça - a política social na ordem brasileira. 2 ed. Rio de Janeiro: Campus, 1987.

. Horizonte do desejo: instabilidade, fracasso coletivo e inércia social. 2aㅡ ed. Rio de Janeiro: FGV Editora, 2006.

SELISTER, R. Porto Alegre gerencia o lixo com iniciativas que preservam o meio ambiente e ajudam a população. O Sul. Porto Alegre. Caderno reportagem, p. 10, 30 set., 2005.

SILVA, J. P. da. Cidadania e reconhecimento. In: AVRITZER, L. \& DOMINGUES, J. M. (Orgs.). Teoria social e modernidade no Brasil. Belo Horizonte: UFMG, 2000. p. 123-135.

. Teoria crítica na modernidade tardia: sobre a relação

entre redistribuição e reconhecimento (versão preliminar). Texto apresentado no GT25 Teoria Social e a Multiplicidade da Modernidade do XXIX Encontro Anual da ANPOCS. Caxambu. 2005.

SILVEIRA, C. M. Reciclagem, participação política e gênero: as múltiplas faces de uma experiência local. Versão preliminar dos textos para discussão. Governo Local e Desigualdades de Gênero Fórum de discussão promovido pela Fundação Getúlio Vargas. São Paulo. P. 109-131, 2002. 
SOUZA, J. Uma teoria crítica do reconhecimento. Lua Nova. São Paulo, n. 50, p. 133-158, 2000.

. A construção social da subcidadania: para uma sociologia política da modernidade periférica. Belo Horizonte: Editora UFMG; Rio de Janeiro: IUPERJ, 2003.

. A gramática social da desigualdade brasileira. Revista Brasileira de Ciências Sociais. São Paulo. V. 19, n. 54, p. 79-96, 2004.

TAYLOR, C. A política de reconhecimento. p. 45-94. In: GUTMANN, A. (Org.). Multiculturalismo: examinando a política de reconhecimento. Lisboa: Instituto Piaget, 1994a..

. La ética de la autenticidad. Barcelona: Paidós, 1994b.

THOMPSON, E. P. Costumes em comum: estudos sobre a cultura popular tradicional. São Paulo: Companhia das Letras, 1998.

ZALUAR, A. Condomínio do Diabo. Rio de Janeiro: Revan/Editora da UFRJ, 1994.

ZERO HORA. O suor dos que tracionam carrinhos. Porto Alegre. Ano 40, n. 13.898, p. 33, 09 set., 2003.

. Metade do lixo seco é recolhida por catadores na capital. Porto Alegre. Ano 42, n. 14.702, p. 54, 25 nov., 2005.

\begin{abstract}
Conflicts over recognition within "peripheral modernity": between equality and distinction.

Our article begins with the argument that the category of recognition, when used within the context of peripheral modernity, implies a social configuration that is quite differentiated from the context in which it was originally elaborated. This is necessary for our ensuing discussion of how struggles for recognition can in the end provide a basis for and legitimate social inequality in Brazil. In countries of this sort, access to social recognition tends to be built not through struggles for recognition as subjects who are bearers of rights but on the contrary, through the struggle to mark out a difference that makes it possible for them to access the material and symbolic gains associated with this differentiated position. In order to explore the analytic possibilities that this argument opens up, we look at
\end{abstract}


collective organizing experiences of collectors of recyclable materials in the state of Rio Grande do Sul. We demonstrate that, in opposition to the discourses and intentions that undergird the organizations we researched, the struggles for recognition that they undertake are to a large extent marked by their effort to differentiate themselves from others who find themselves in a similarly subaltern condition, thus establishing competition for access to particular scarce material and symbolic goods..

Keywords: peripheral modernity, social recognition, distinction, catadores. 